\title{
Author Correction: Analysis of human metabolism by reducing the complexity of the genome-scale models using redHUMAN
}

\author{
Maria Masid (1), Meric Ataman (D) \& Vassily Hatzimanikatis (10)
}

Correction to: Nature Communications https://doi.org/10.1038/s41467-020-16549-2, published online 4 June 2020.

The original version of this Article's Acknowledgement section incompletely read:

This project has received financial support from the European Union's Horizon 2020 research and innovation programme under the Marie Skłodowska Curie Grant Agreement No. 675585 SyMBioSys and under Grant Agreement No. 686070.

Instead of:

We would like to thank Dr. G. Fengos, Dr. J.P. Vieira and Dr. D.R. Weilandt for constructive discussions and feedback; and Dr. K. Butler for valuable comments proofreading this paper. This project has received financial support from the European Union's Horizon 2020 research and innovation programme under the Marie Skłodowska Curie Grant Agreement No. 675585 SyMBioSys, and under Grant Agreement No. 686070, and from the RTD project MicroScapeX (grant 2013/158) funded by SystemsX.ch, the Swiss Initiative for Systems Biology evaluated by the Swiss National Science Foundation.

This has now been corrected in both the PDF and HTML versions of the Article.

Published online: 23 July 2020

\footnotetext{
(c) (i) Open Access This article is licensed under a Creative Commons Attribution 4.0 International License, which permits use, sharing, adaptation, distribution and reproduction in any medium or format, as long as you give appropriate credit to the original author(s) and the source, provide a link to the Creative Commons license, and indicate if changes were made. The images or other third party material in this article are included in the article's Creative Commons license, unless indicated otherwise in a credit line to the material. If material is not included in the article's Creative Commons license and your intended use is not permitted by statutory regulation or exceeds the permitted use, you will need to obtain permission directly from the copyright holder. To view a copy of this license, visit http://creativecommons.org/licenses/by/4.0/.
}

(C) The Author(s) 2020 